\title{
Educação Popular em Saúde, mais do que nunca!
}

E se podemos parecer sermos hoje menos do que fomos ontem, / sabemos também que somos agora mais indispensáveis do que nunca. / Porque mais do que nunca, mais do que sempre, / trata-se de salvar o homem de si mesmo e a si mesmo / trata-se de reverdecer o mundo e recriar a vida / e quem aprende e educa vive aí o seu lugar essencial.

Carlos Rodrigues Brandão (2014a)

Quando concebemos esta edição, fruto da parceria entre a Revista de Educação Popular e o Grupo Temático de Educação Popular e Saúde da Associação Brasileira de Saúde Coletiva (GT EPS-ABRASCO), tínhamos em mente a importância da atualização das reflexões sobre o agir em saúde a partir da perspectiva da educação popular, de modo a nos apontar caminhos para compreender e superar um cenário cada vez mais sombrio que nos assolava e que aumentava os desafios para o cuidado em saúde.

Com o fortalecimento do neoliberalismo e os consequentes retrocessos nas políticas que garantiam um mínimo de seguridade social no Brasil, vínhamos vivendo a ampliação de um quadro de piora das condições de vida pelo aumento do desemprego, da precarização das relações de trabalho e do desinvestimento em políticas públicas de saúde, educação, cultura, meio ambiente, reforma agrária, agricultura familiar, dentre tantas outras áreas que estruturam, ou desestruturam, a vida. Concomitantemente, assistimos a reemergência de doenças e o recrudescimento de outras, bem como o aumento das morbidades e das mortalidades, do feminicídio, da LGBTQI+fobia, de atos e discursos racistas, da intolerância religiosa, da degradação do meio ambiente, do envenenamento dos nossos alimentos, da criminalização da pobreza, da legitimação do extermínio das populações pobres etc. Mais do que nunca, se fazia necessário gerar um pensamento utópico, encharcado de esperança da mudança deste mundo feio, o que implicaria, na "denúncia de como estamos vivendo e o anúncio de como poderíamos viver" (FREIRE, 2016, p. 137).

No entanto, já não bastasse lidar com tantas situações-limite, entramos no ainda mais conturbado 2020 - ano em que o SARS-CoV-2, agente causador da COVID-19 (Doença do Coronavírus na sigla em inglês), se espraia facilmente e rapidamente por este mundo globalizado. A sua presença, desde a luxuosa e espaçosa Avenida Paulista às paupérrimas e estreitas vielas do Complexo do Alemão, alimentava o discurso de muitos de que a pandemia era democrática, de que estaríamos "no mesmo barco". Doce ilusão: enquanto alguns estão 
esperando passar tudo isso de seus iates, interconectados mundialmente com banda larga, outros tentam sobreviver à tormenta em cima de isopores à deriva, sendo desconectados do mundo virtual quando se finda o pacote diário de acesso à internet por celular. Enquanto uma patroa recém-chegada de viagem à Itália (epicentro da pandemia na Europa naquele momento) pode ficar em casa em tempos de distanciamento físico, a empregada doméstica negra, que continua trabalhando para ela, não tem a mesma oportunidade, o que lhe custa sua própria vida, a vida de mais uma vítima da necropolítica que vivemos diariamente.

A pandemia, portanto, não tem nada de democrática. Pelo contrário, acentua as fragilidades da nossa democracia inconclusa, agravando, ainda mais, a difícil situação que diversos grupos sociais já vinham enfrentando para o exercício da cidadania, da autonomia, do bem viver. Na saúde, respostas pautadas somente no modelo biomédico têm mostrado o grande fosso entre as orientações preventivas de "isolamento social" com o mundo da vida de grande camada da população que não possui condições de poder desenvolvê-las em seu cotidiano. Continuamos vivendo uma "crise de interpretação" (VALLA, 1998), de um fazer em saúde hermético às especificidades dos diversos contextos socioculturais que circundam o processo saúde-doença-cuidado. Continuamos vivendo uma crise no nosso Sistema Único de Saúde (SUS). Maior sistema de saúde público, gratuito e universal do mundo, o SUS é projeto de cidadania que confronta o ideário de saúde enquanto mercadoria para compreender saúde como um direito humano.

Em meio a tantas crises, resgatar o pensar e o agir críticos trata-se, mais do que nunca, de um imperativo ético para a transformação social, pois, ainda que tais crises nos ofertam riscos e perigos, são também momentos de oportunidade, de possibilidade de construção de atos-criadores (ABRASCO, 2020). Nutrir-se do horizonte político-pedagógico da educação popular e aprender com experiências concretas, orientadas por tal referencial, pode ser oportuno para esperançar coletivamente inéditos-viáveis, que apontam para a construção de outros mundos possíveis, afinal, "a latente crise nos sistemas capitalista e biomédico de saúde nos apresenta a possibilidade de construir um projeto democrático e popular, pautado no diálogo, na emancipação, na amorosidade e no bem viver" (GT EPS-ABRASCO, 2020, não paginado).

Neste contexto, podemos observar a organização de diversas estratégias pautadas pela educação popular, pelo diálogo e pela construção compartilhada do conhecimento. Diversas entidades, como a ABRASCO e a Rede Unida, têm organizado espaços virtuais para reflexão acerca da pandemia, bem como análise crítica das práticas, buscando construir possibilidades e respostas. No âmbito do GT EPS-ABRASCO, uma série de ações tem sido realizada, a 
começar pelo encontros virtuais com maior frequência desde antes da quarentena, com intuito de acolhermos uns aos outros e de trocar experiências. Outro exemplo de construção de proposições efetivas são os projetos de extensão, em que diversos membros do GT estão envolvidos, como o Curso de Formação "Participação, Educação Popular e Promoção da Saúde: saberes, ideias e práticas" e o Projeto "Uma imagem, uma mensagem... expressões de profissionais de saúde no contexto do COVID-19"2. Não temos aqui a pretensão de explorar as centenas de estratégias concebidas pelo Brasil afora, mas, sim, reforçar que, mais do que nunca, o pensamento freiriano tem encharcado diversas experiências. Por isso, a necessidade de manter vivos os espaços de ação-reflexão-ação sobre o agir em saúde a partir da educação popular.

Com esta perspectiva, esta Edição Temática em Educação Popular em Saúde da Revista de Educação Popular traz artigos originais de pesquisa, relatos de experiência, pontos de vistas e entrevista que nos oxigenam em "tempos pandêmicos".

As membras e membros do nosso grupo temático foram convidadas/os a atualizarem as discussões desenvolvidas no II Seminário Temático do GT EPS-ABRASCO ${ }^{3}$, que ocorreu nos dias 4 e 5 de fevereiro de 2020, em Parnaíba, Piauí, como atividade preparatória do VI Encontro Nacional e I Encontro Latinoamericano de Educação Popular e Saúde. Os sete painéis temáticos e o espaço avaliativo deste seminário puderam problematizar a Educação Popular em Saúde a partir da dimensão epistemológica, da análise de conjuntura, da produção do conhecimento, do processo de pesquisa, dos processos formativos, da concepção sobre educação e do uso das múltiplas linguagens. As reflexões construídas coletivamente nestes espaços foram sistematizadas em seis produções que compõem esta edição: cinco pontos de vista e um artigo original.

Os demais manuscritos derivaram de chamada pública divulgada pela Revista Educação Popular em janeiro de 2020. Tratam-se de artigos originais e relatos de experiências que barquejam rumo ao horizonte ético-político da educação popular pelos diversos cantos e recantos brasileiros, do Rio Grande do Norte ao Rio Grande do Sul, bem como de entrevista com Oscar Jara Holliday, diretor do Centro de Estudos e Publicações de Alforja, em São José, Costa Rica. São mãos, pés, corações e mentes de graduandos, residentes em saúde,

\footnotetext{
${ }^{1}$ Curso desenvolvido no âmbito do Projeto PINAB - Práticas Integrais de Promoção da Saúde e Nutrição na Atenção Básica em Saúde da Universidade Federal da Paraíba (UFPB).

${ }^{2}$ Projeto desenvolvido por extensionistas do Laboratório Interdisciplinar de Direitos Humanos e Saúde (LIDHS) do Instituto de Estudos em Saúde Coletiva da Universidade Federal do Rio de Janeiro (IESC/UFRJ).

${ }^{3}$ Para mais informações e acesso aos materiais e discussões do II Seminário Temático do GT EPS-ABRASCO, acesse a página do evento em: https://www.abrasco.org.br/site/gteducacaopopularesaude/2020/01/27/gteducacao-popular-em-saude-organiza-2o-seminario-tematico/.
} 
mestrandos, doutorandos, docentes, técnicos administrativos e pesquisadores que corporificam o agir crítico e a responsabilidade social da Universidade nos seus processos de ensino, de pesquisa e de extensão. Há também experienciações de educadores populares em saúde, que a partir do seu fazer-pensar-fazer, contribuem para as práticas junto a grupos populares em organizações comunitárias ou no processo formativo do Curso de Aperfeiçoamento em Educação Popular em Saúde, o EdPopSUS, maior estratégia formativa voltada para a implementação da Política Nacional de Educação Popular em Saúde no âmbito do Sistema Único de Saúde (PNEPS-SUS).

Num contexto de ataque às universidades, à pesquisa brasileira, às organizações de base popular, ao EdPopSUS, à PNEPS-SUS e ao SUS como um todo, estes escritos, que partem destes lugares, se configuram como atos de resistência, de re-existência, de uma existência indignada que não aceita dócil e passivamente a distorção da vocação humana do ser, provocada pelo processo desumanizador que vivemos, de uma existência que tem a coragem de assumir que "mudar é difícil, mas é possível" (FREIRE, 2014, p. 207) e urgente, de uma existência que se sabe construtora de uma transição para um amanhã outro em que "mais do que nunca se faz indispensável o desenvolvimento de uma mente crítica" (FREIRE, 2016a, p. 88) e de um fazer esperançoso.

Mais do que nunca, Paulo Freire continua conosco em nossas andanças e criacionices. Mais do que nunca, Marias, Mahins, Marielles e Malês precisam ser ouvidas/os, hoje e sempre. Mais do que nunca, poesias abrem amanheceres, guardam pregos que farfalham, encolhem rios e esticam horizontes. Mais do que nunca, o formigueiro grita para pisar ligeiro. Mais do que nunca, povos tradicionais nos ensinam um outro jeito de olhar este mundo e relacionar-se com ele. Mais do que nunca, Josés Marmos, Terezas Ramos, Victors Vallas e tantas outras e tantos outros que começaram a construção de legados históricos vivem... Mais do que nunca estamos de pé resistindo, lutando, agindo!

Estamos de pé e com os olhos no agora e no horizonte não somente semeamos, resistimos. Não apenas colhemos, nós lutamos. Não apenas esperamos, nós agimos. Porque mais do que ontem, mais do que nunca somos uma gente da terra e do campo [...]

Carlos Rodrigues Brandão (2014b) 
Boa leitura!

César Augusto Paro, Grasiele Nespoli e Luanda de Oliveira Lima

Integrantes do GT EPS/ABRASCO

Organizadores

\section{Referências}

ABRASCO - Associação Brasileira de Saúde Coletiva. Educação Popular em Saúde e Pandemia: diálogos e oportunidades. 2020. (2h21min). Disponível em:

https://www.youtube.com/watch?v=8sSFt3oUAUk. Acesso em: 27 maio 2020.

BRANDÃO, C. R. "Somos uma gente que semeia e cria": palavras sobre as culturas e os saberes da Gente do Campo. [Internet] 2014b. Disponível em:

http://www.apartilhadavida.com.br/wp-content/uploads/escritos/ARTE/POESIA\%20-

\%20LIVRE/AA.\%20SOMOS\%20UMA\%20GENTE\%20QUE\%20CRIA.pdf. Acesso em: 27

maio 2020.

BRANDÃO, C. R. Aprender com vida, dialogar com a vida, ensinar pela vida: cantata para voz, vento, viola e violino em três movimento. [Internet] 2014a. Disponível em: http://www.apartilhadavida.com.br/wpcontent/uploads/escritos/ARTE/CANTARES,\%20CANTIGAS\%20CANTATAS/APRENDE R\%20COM\%20A\%20VIDA,\%20DIALOGAR\%20COM\%20A\%20VIDA,\%20EDUCAR\%2 0PARA\%20A\%20VIDA.pdf. Acesso em: 27 maio 2020.

FREIRE, P. Educação e mudança. Tradução Lilian Lopes Martin. 37. ed. rev. atua. São Paulo: Paz e Terra, 2016a.

FREIRE, P. Pedagogia da indignação: cartas pedagógicas e outros escritos. 3. ed. São Paulo: Paz e Terra, 2016b.

FREIRE, P. Pedagogia dos sonhos possíveis. São Paulo: Paz e Terra, 2014.

GT EPS-ABRASCO - Grupo Temático de Educação Popular e Saúde da Associação Brasileira de Saúde Coletiva. Educação popular em tempos de pandemia: todas as certezas são provisórias. Boletim ANPEd, ano IX, n. 55, 2020. Disponível em:

http://www.anped.org.br/news/educacao-popular-em-tempos-de-pandemia-todas-certezassao-provisorias-gt-06. Acesso em: 27 maio 2020.

VALLA, V. V. Sobre participação popular: uma questão de perspectiva. Cadernos de Saúde Pública, Rio de Janeiro, v. 14, sup. 2, p. 7-18, 1998. Doi: 10.1590/S0102311X1998000600002. 